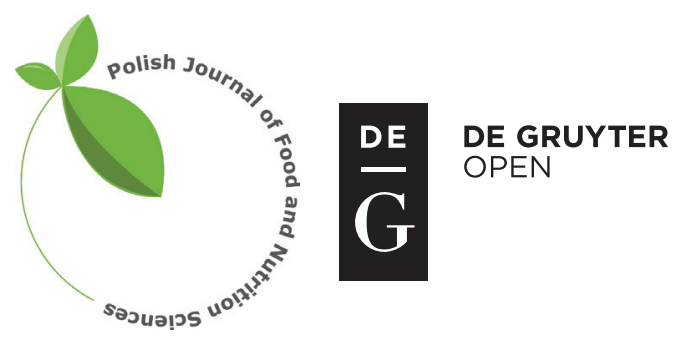

Pol. J. Food Nutr. Sci., 2016, Vol. 66, No. 2, pp. 93-98 DOI: $10.1515 /$ pjfns-2015-0042 http://journal.pan.olsztyn.pl

Original article

Section: Food Chemistry

\title{
Combined Effects of Blue and Ultraviolet Lights on the Accumulation of Flavonoids in Tartary Buckwheat Sprouts
}

\author{
Hongbin Ji*, Wen Tang, Xiaoli Zhou, Ying Wu \\ Department of Food Science and Technology, School of Perfume and Aroma Technology, Shanghai \\ Institute of Technology, 100 Haiquan Road, Fengxian District, Shanghai 201418, China
}

Key words: blue light, UV-A/UV-C, tartary buckwheat sprouts, flavonoids

The effects of blue and UV-A $(365 \mathrm{~nm}) / \mathrm{UV}-\mathrm{C}(254 \mathrm{~nm})$ or their combinations on the levels of total flavonoids, rutin, quercetin, phenylalanine ammonialyase (PAL), chalcone isomerase (CHI), rutin degrading enzymes (RDEs) and 1,1-diphenyl-2-picrylhydrazyl (DPPH) radical scavenging activity in tartary buckwheat sprouts were investigated in this study. The total flavonoids content in the tartary buckwheat sprouts irradiated with blue light followed by UV-C (BL+UV-C) raised by $10 \%$, compared with the opposite combination sequence (UV-C + BL). However, blue light did not show the same results when combined with UV-A, and their combinations on the accumulation of total flavonoids were still lower than that of UV-A/UV-C. Key enzymes (PAL,CHI and RDEs) revealed a significant correlation with total flavonoids in tartary buckwheat sprouts.

\section{INTRODUCTION}

Tartary buckwheat in the form of noodles, flour and steamed bun is a commonly consumed food in Asian countries. In recent years, tartary buckwheat (Fagopyrum esculentum) has received increasing attention due to its abundant nutritive compounds. Tartary buckwheat sprouts are new vegetable products that have also attracted a lot of attention because they have not only high levels of flavonoids [Kim et al., 2004] but also some beneficial functions on blood pressure [Nakamura et al., 2013]. Flavonoids as a large class of second metabolites are widely distributed in many plants including tartary buckwheat and display antioxidant activity in plants [Pietta, 2000]. Flavonoids are synthesized by the phenylpropanoid metabolic pathway in which the amino acid phenylalanine is used to produce 4-coumaroyl-CoA catalyzed by the enzyme - phenylalanine ammonialyase (PAL) [Koes et al., 1994]. Chalcone isomerase (CHI), a second key enzyme, mediates the phenylpropanoid pathway for the synthesis of flavonoids [Winkel-Shirley, 2001].

Many factors such as lights [Cortell \& Kennedy, 2006] and rare earth elements [Liang et al., 2006] have effects on the accumulation and distribution of flavonoids. Wang et al. [2013] reported that the total flavonoids content in tartary buckwheat increased by adding the additives $\left(\mathrm{Al}^{3+}, \mathrm{Cu}^{2+}\right.$, and $\mathrm{Zn}^{2+}$ ) when their concentration was in a certain range and decreased when their concentration was beyond a certain range. It was also reported that in the callus-cultured Malva

\footnotetext{
* Corresponding Author: Tel./Fax: +86 21 60873514;

E-mail: jihongbin88@yahoo.com (Hongbin Ji)
}

neglecta cells, UV irradiation increased flavonoids and anthocyanin content significantly compared with darkness [Khatami \& Ghanati, 2011], and blue light increased rutin and quercetin content in tartary buckwheat sprouts [Tsurunaga et al., 2013].

Ultraviolet as a common natural environment factor affected the morphological growth, biochemical and physiological responses of plants [Caldwell et al., 1998; Zhang et al., 2003]. It was traditionally divided into three wavelengths: UV-C (200-280 nm), UV-B (280-320 nm), UV-A (320-400 nm). Blue light was another important environmental factor involved in a wide range of plant processes such as phototropism, photomorphogenesis, stomatal opening, and photosynthesis [Whitelam \& Halliday, 2007], and it could lead to higher plant biomass [Matsuda et al., 2008]. Several studies indicated that the chalcone synthase (CHS), a key enzyme for flavonoids biosynthesis, was involved in synergistic effect of UV and blue light [Jenkins, 1997]. Ohl et al. [1989] reported that blue light increased the response to a subsequent UV-B pulse, and it led to the increase of CHS impression. However, there are only few studies on the effect of blue light and UV-A/UV-C on levels of flavonoids and flavonoids biosynthesis related enzymes in tartary buckwheat sprouts. Hence, we examined the effects of the combined effects of blue and UV-A (356 nm)/ UV-C $(254 \mathrm{~nm})$ lights or their combinations on flavonoids of tartary buckwheat sprouts.

\section{MATERIAL AND METHODS}

\section{Material and chemical reagents}

Dried tartary buckwheat seeds (Fagopyrum esculentum) called HeiFeng NO.1 in the experiments were obtained from 


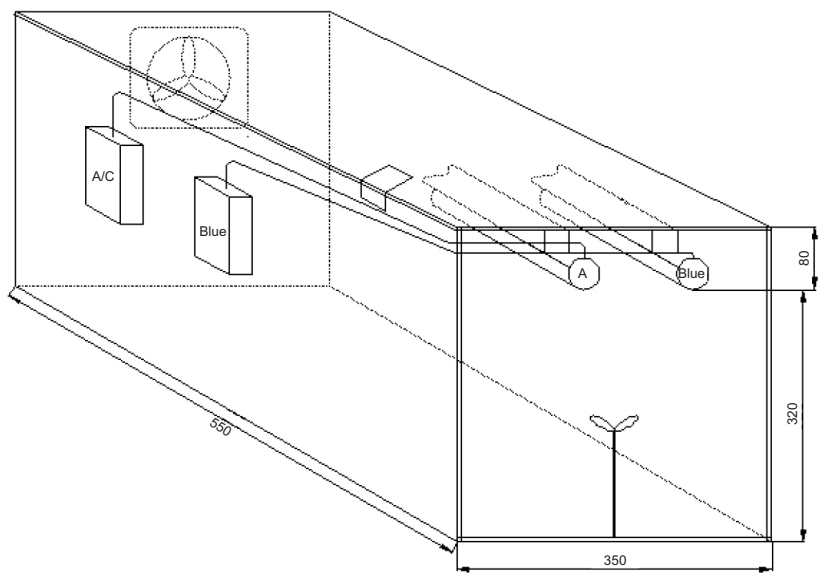

FIGURE 1. Irradiation equipment for tartary buckwheat sprouts (units in $\mathrm{mm}$ ). A/C shows switch of UV-A/UV-C and blue shows switch of blue light.

TABLE 1. Intensity of irradiation from different light.

\begin{tabular}{lc}
\hline Source & Intensity $\left(\mathrm{W} / \mathrm{m}^{2}\right)$ \\
\hline Control(darkness) & 0 \\
BL+UV-A & 136.26 \\
UV-A+BL & 136.26 \\
BL+UV-C & 136.26 \\
UV-C+BL & 136.26 \\
Blue & 66.93 \\
UV-A & 70.32 \\
UV-C & 70.32 \\
\hline
\end{tabular}

Shanxi province, China. Chemical reagents as rutin (purity $>99 \%$ ) and quercetin (purity >99\%) were purchased from Sigma-Aldrich (USA) and the other reagents were purchased from Sinopharm Chemical Reagent Co., Ltd.

\section{Germination procedures}

Tartary buckwheat seeds were sterilized with $1.25 \%(\mathrm{w} / \mathrm{v})$ sodium hypochlorite at room temperature for $30 \mathrm{~min}$ to eliminate micro-organisms, and then washed three times with distilled water. Before germination, seeds were soaked in tap water at $25 \pm 1{ }^{\circ} \mathrm{C}$ in artificial climate incubator for $12 \mathrm{~h}$. Then, 20 g seeds were spread into each tray $(30 \mathrm{~cm} \times 40 \mathrm{~cm})$ with three pieces of filter paper. The seeds were incubated at $98 \%$ $\mathrm{RH}$ and $30 \pm 1^{\circ} \mathrm{C}$ for 3 days. After germination, the sprouts were carefully washed with distilled water and removed theas soon as possible and stored at $-80^{\circ} \mathrm{C}$ until their use. Some sprouts were dried at $-80^{\circ} \mathrm{C}$ for $24 \mathrm{~h}$, ground into powder and passed through a 20-mesh screen sieve.

\section{Lights irradiation treatments}

Blue light fluorescent lamps $(15 \mathrm{~W})$ were purchased from Toshiba and UV lamps (16 W, GL-9406) were purchased from Shanghai Chaojing science and Technology Co. Ltd. The irradiation equipment was designed according to Tsurunaga et al. [2013] with some modifications and it is shown in Figure 1.
The irradiation intensity of the light sources is shown in Table 1 . The seeds were cultivated in darkness for $60 \mathrm{~h}$ to allow them to germinate, and then were irradiated by UV-A/UV-C and blue light or their combinations for $12 \mathrm{~h}$. Their combinations were shown as follows: UV-A+Blue light (UV-A+BL), Blue light+UV-A (BL+UV-A), UV-C+Blue light (UV-C+BL), Blue light $+\mathrm{UV}-\mathrm{C}(\mathrm{BL}+\mathrm{UV}-\mathrm{C})$. For example, UV-A+BL: tatary buckwheat sprouts were irradiated with UV-A for $6 \mathrm{~h}$ and followed by blue light for another $6 \mathrm{~h}$. Darkness was set as control.

\section{Determination of sprouts length}

Three days later, sprouts from 10 replicated plants per treatment were measured from the surface of the bottom to the top of the sprouts.

\section{Determination of total flavonoids}

The determination of total flavonoids was based on the method of Stockova et al. [2009] with some modifications. One gram of freeze dried tartary buckwheat sprouts was immersed in $50 \mathrm{~mL} 60 \%(\mathrm{v} / \mathrm{v})$ ethanol, and put into $70^{\circ} \mathrm{C}$ water bath for $6 \mathrm{~h}$, and then centrifuged at $3000 \times \mathrm{g}$ for $10 \mathrm{~min}$. The supernatant was the extract sample. Then, $1 \mathrm{~mL}$ of sample extract was transferred to a $10 \mathrm{~mL}$ volumetric flask and $2 \mathrm{~mL}$ of $0.1 \mathrm{~mol} / \mathrm{L}$ aluminum chloride solution and $3 \mathrm{~mL}$ of $1 \mathrm{~mol} / \mathrm{L}$ potassium acetate were added. The mixture was diluted to scale $(10 \mathrm{~mL})$ with $60 \%(\mathrm{v} / \mathrm{v})$ ethanol, mixed well and kept in darkness for $30 \mathrm{~min}$. The absorbance at $420 \mathrm{~nm}$ of the mixture after reaction was measured. Rutin was used to plot a standard curve (shown as follows), and total flavonoids were expressed as rutin equivalents.

$$
\mathrm{A}_{420}=21.923(\mathrm{mg} / \mathrm{mL}) \text { rutin }-0.028, \mathrm{R}^{2}=0.993
$$

\section{Assay for PAL activity determination}

The procedure of extraction and measurement was performed according to Chen et al. [2003] and Assis et al. [2001] with some modifications. Fresh buckwheat sprouts $(1.0 \mathrm{~g})$ without testa (seed coat) were ground with mortar and pestle at $0^{\circ} \mathrm{C}$ in $5 \mathrm{~mL} 0.1 \mathrm{~mol} / \mathrm{L}$ borated buffer $(\mathrm{pH} 8.8)$ containing $1 \mathrm{mmol} / \mathrm{L}$ ethylene diamine tetraacetic acid (EDTA), $5 \mathrm{mmol} / \mathrm{L}$ mercaptoethanol, $1 \%$ (w/v) polyvinylpyrrolidone (PVP) and 1\% (v/v) glycerol, and then centrifuged at $12,000 \times \mathrm{g}, 4^{\circ} \mathrm{C}$ for $20 \mathrm{~min}$. The supernatant was used as a resource of crude enzyme. Total protein amount was determined according to Bradford method with bovine serum albumin as a standard $\left(\mathrm{A}_{595}=0.0219\right.$ bovine serum albumin $\left.(\mu \mathrm{g} / \mathrm{mL})-0.028, \mathrm{R}^{2}=0.9991\right)$. A $0.5 \mathrm{~mL}$ aliquot of crude enzyme extract was added to $3 \mathrm{~mL} 0.1 \mathrm{~mol} / \mathrm{L}$ borated buffer $(\mathrm{pH} 8.8)$, and $1.5 \mathrm{~mL}$ of substrate $(0.2 \mathrm{~mol} / \mathrm{L} \mathrm{L}$-phenylalanine). The mixture was incubated in a water bath at $30^{\circ} \mathrm{C}$ for $1 \mathrm{~h}$. PAL activity was estimated by measuring the variation of the absorbance at $290 \mathrm{~nm}\left(\mathrm{~A}_{290}\right)$ per hour. Variation of $0.001 \mathrm{~A}_{290}$ was defined as one unit (U) and specific enzyme activity was defined as one unit per milligram of protein.

\section{Assay for CHI activity determination}

The determination of CHI activity was carried out according to the method of Lister et al. [1996] and Wang et al. 
[2013] with some modifications. Sprouts were ground with mortar and pestle at $0^{\circ} \mathrm{C}$ in $5 \mathrm{~mL}$, pH 8.0 sodium phosphate buffer, and then centrifuged at $10,000 \times \mathrm{g}, 4^{\circ} \mathrm{C}$ for $20 \mathrm{~min}$. The supernatant was used as a resource of crude enzyme. A $0.75 \mathrm{~mL}$ aliquot of crude enzyme liquid was added to the mixture containing $2 \mathrm{~mL}$ of $0.05 \mathrm{~mol} / \mathrm{L}$ Tris- $\mathrm{HCl}$ buffer ( $\mathrm{pH} 7.4), 7.5 \mathrm{mg} / \mathrm{mL}$ of bovine serum albumin (BAS), $50 \mathrm{mmol} / \mathrm{L}$ of $\mathrm{KCN}$ and $50 \mu \mathrm{L}$ of $1 \mathrm{mg} / \mathrm{mL}$ hydroxylated chalcone. The reaction was conducted at $30^{\circ} \mathrm{C}$ for $30 \mathrm{~min}$. The variation of absorbance at $381 \mathrm{~nm}\left(\mathrm{~A}_{381}\right)$ was used to estimate $\mathrm{CHI}$ activity. Variation of $0.001 \mathrm{~A}_{381}$ was defined as one unit (U) and specific enzyme activity was defined as one unit per milligram of protein.

\section{Assay for RDEs activity determination}

The RDEs activity was determined according to the procedure of Chen et al. [2011] with some modification. One gram of tartary buckwheat sprout powder was extracted in $5 \mathrm{~mL}$ of $0.2 \mathrm{~mol} / \mathrm{L}$ acetate buffer $(\mathrm{pH} 4.0)$ at $4^{\circ} \mathrm{C}$ for $3 \mathrm{~h}$, and then was centrifuged at $10,000 \times \mathrm{g}, 4^{\circ} \mathrm{C}$ for $20 \mathrm{~min}$. The supernatant was the crude enzyme extract and was stored at $4^{\circ} \mathrm{C}$ until its use. $0.04 \mathrm{~mL}$ of enzyme extraction reacted with $0.15 \mathrm{~mL}$ of enzyme substrate $(0.1 \mathrm{~g}$ of rutin dissolved in methanol, which was diluted 10 times by acetic acid buffer solution) at $50^{\circ} \mathrm{C}$ water bath for $3 \mathrm{~min}$ and $0.8 \mathrm{~mL}$ methanol was immediately used to stop the reaction after $3 \mathrm{~min}$. Then, it was diluted by $5 \mathrm{~mL}$ of diluents liquid $(16.8 \mathrm{~mL}, 0.2 \mathrm{~mol} / \mathrm{L}$ acetate buffer was added to $100 \mathrm{~mL}$ volumetric flask, and diluted to the scale by methanol). The absorbance of sample was measured at selected wavelengths $(343.3 \mathrm{~nm}$ and $372 \mathrm{~nm})$. The variation of absorbance of 0.001 at $343.3 \mathrm{~nm}$ and $372 \mathrm{~nm}$ was defined as one unit (U) and the RDEs activity was $\mathrm{U} / \mathrm{mg}$ dry matter.

\section{DPPH radical scavenging activity}

DPPH radical scavenging activity (RAS) was measured according the method described by Takahata et al. [2011] and Nakajima et al. [2009] with some modifications. Briefly, $5 \mathrm{~mL}$ of the previously prepared $60 \%(\mathrm{v} / \mathrm{v})$ ethanol extract was added to $5 \mathrm{~mL}, 200 \mu \mathrm{mol} / \mathrm{L} \mathrm{DPPH}$ in ethanol. The mixture was incubated at room temperature in darkness for $30 \mathrm{~min}$, and the absorbance was measured at $517 \mathrm{~nm}\left(\mathrm{~A}_{\mathrm{T}}\right)$. Pure DPPH solution was set as control and its absorbance at $517 \mathrm{~nm}$ was $\mathrm{A}_{0}$ The DPPH radical scavenging activity (RAS) was calculated as follows:

$$
\operatorname{RAS}(\%)=\left(\mathrm{A}_{0}-\mathrm{A}_{\mathrm{T}}\right) \times 100 / \mathrm{A}_{0}
$$

\section{HPLC analysis for rutin and quercetin}

The content of rutin and quercetin in tartary buckwheat sprouts was analyzed by using a quantitative SHIMADZU HPLC system, consisting of SHIMADZU 20AD pumps, a SHIMADZU SIL-20A auto sampler and a SHIMADZU SPD-M20A detector. Samples were separated on a reversed phase Phenomenex $\mathrm{C}_{18}$ column $(4.6 \times 150 \mathrm{~mm}, 5 \mu \mathrm{m}$ particle size) and all the samples were passed through $0.22 \mu \mathrm{m}$ millipore filter. Acetonitrile and $0.05 \%(\mathrm{v} / \mathrm{v})$ phosphoric acid were used as solvents, pumped at a flow rate of $1 \mathrm{~mL} / \mathrm{min}$ for rutin determination and $0.8 \mathrm{~mL} / \mathrm{min}$ for quercetin determination.
The UV detection was performed at $256 \mathrm{~nm}$. Quantifications of rutin and quercetin at different concentrations were used to plot a standard curve.

\section{Statistical analysis}

All the data were expressed as means \pm SD at three replicates of each sample. Analysis of variance and significant difference analysis via one-way ANOVA followed by Duncan method $(P<0.05)$ were conducted by using SPSS 18.0 software.

\section{RESULTS AND DISCUSSION}

\section{Effect of light combinations on growth of tartary buckwheat sprouts}

The length of control and irradiated sprouts was measured after $72 \mathrm{~h}$ and the results are shown in Figure 2. Blue light significantly increased length of sprouts, and UV-C dwarfed the sprouts. Blue light in combination with UV-A or UV-C led to higher length of sprouts than UV-A and UV-C alone. Thus, it was obvious that blue light enhanced the growth of tartary buckwheat sprouts.

\section{Effect of light combinations on the levels of total flavonoids and PAL, CHI, RDEs activity}

Total flavonoids content in tartary buckwheat sprouts was greatly sensitive to blue light and UV-A/UV-C or their combinations (Figure 3). The total flavonoids content in sprouts irradiated with UV-C, UV-A and blue light increased respectively $56.1 \%, 51.2 \%, 24.2 \%$ compared with darkness. The highest content of total flavonoids was observed in the tartary buckwheat sprouts irradiated with UV-C (47.52 mg/g dry matter) or UV-A (46.02 mg/g dry matter). UV-A/UV-C increased in higher extent the total flavonoids content than blue light alone or combined with UV-A/UV-C. As several previous studies reported, both UV-A/UV-C [Khatami \& Ghanati, 2011] and blue light [Saber et al., 1998] in-

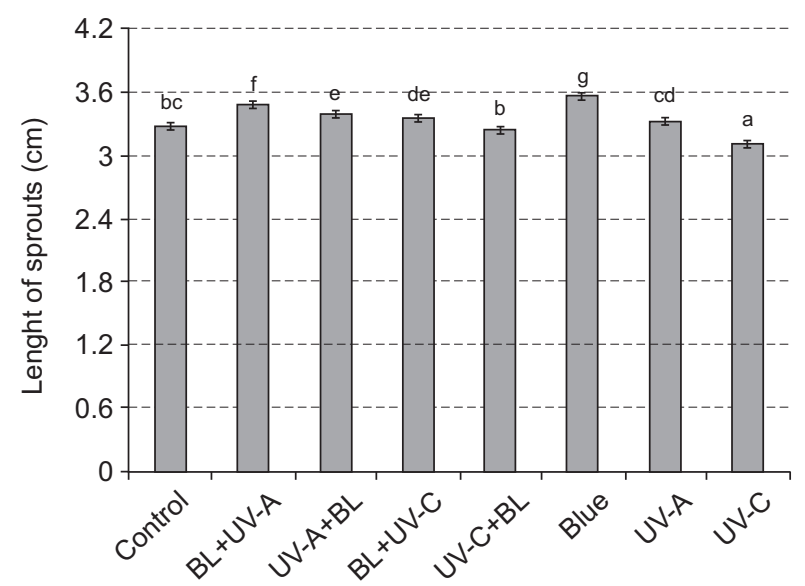

FIGURE 2. Effect of irradiation with different light combinations on the length of tartary buckwheat sprouts. Vertical bars indicate the standard deviation. BL+UV-A: irradiation with blue light followed by UV-A; UV-A+BL: irradiation with UV-A followed by blue light; BL+UV-C: irradiation with blue light followed by UV-C; UV-C+BL: irradiation with UV-C followed by blue light. Different letters show significant difference $(P<0.05)$. 
TABLE 2. Effect of light combinations on PAL, CHI and REDs activity in tartary buckwheat sprouts.

\begin{tabular}{lcccc}
\hline & $\begin{array}{c}\text { PAL } \\
(\mathrm{U} / \mathrm{mg} \text { protein })\end{array}$ & $\begin{array}{c}\text { CHI } \\
(\mathrm{U} / \mathrm{mg} \text { protein })\end{array}$ & $\begin{array}{c}\text { RDEs } \\
(\mathrm{U} / \mathrm{mg} \mathrm{DW})\end{array}$ \\
\hline Control & $163.41 \pm 6.75^{\mathrm{a}}$ & $35.78 \pm 3.01^{\mathrm{a}}$ & $21.81 \pm 0.11^{\mathrm{a}}$ \\
BL+UV-A & $287.89 \pm 7.26^{\mathrm{e}}$ & $55.47 \pm 2.51^{\mathrm{bc}}$ & $27.38 \pm 0.26^{\mathrm{cd}}$ \\
UV-A+BL & $246.98 \pm 5.32^{\mathrm{d}}$ & $63.89 \pm 3.62^{\mathrm{c}}$ & $27.58 \pm 0.33^{\mathrm{cd}}$ \\
BL+UV-C & $279.12 \pm 7.11^{\mathrm{e}}$ & $60.26 \pm 3.74^{\mathrm{bc}}$ & $27.06 \pm 1.24^{\mathrm{cd}}$ \\
UV-C+BL & $227.64 \pm 5.65^{\mathrm{c}}$ & $42.92 \pm 2.19^{\mathrm{a}}$ & $24.66 \pm 0.83^{\mathrm{b}}$ \\
Blue & $260.13 \pm 5.51^{\mathrm{d}}$ & $43.83 \pm 3.21^{\mathrm{a}}$ & $25.36 \pm 0.75^{\mathrm{bc}}$ \\
UV-A $(365 \mathrm{~nm})$ & $192.24 \pm 6.57^{\mathrm{b}}$ & $96.84 \pm 2.75^{\mathrm{e}}$ & $27.19 \pm 1.31^{\mathrm{cd}}$ \\
UV-C $(254 \mathrm{~nm})$ & $287.89 \pm 9.41^{\mathrm{e}}$ & $97.92 \pm 1.98^{\mathrm{e}}$ & $28.22 \pm 0.41^{\mathrm{d}}$ \\
\hline
\end{tabular}

Data presented are means \pm standard deviation of the mean for three independent experiments. Different letters show significant differences $(P<0.05)$.

creased the accumulation of flavonoids. However, the effect of blue light on flavonoids was much lower than that of ultraviolet (Figure 3).

Blue light showed different influence on total flavonoids accumulation when combined with UV-A or UV-C. Blue light combined with UV-C increased total flavonoids content significantly $(P<0.05)$ when tartary buckwheat sprouts were irradiated with blue light first $(\mathrm{BL}+\mathrm{UV}-\mathrm{C})$. Total flavonoids content of BL+UV-C was $4.15 \mathrm{mg} / \mathrm{g}$ dry matter, higher than that of UV-C+BL. This effect was not observed when blue light was combined with UV-A (BL+UV-A). Ohl et al. [1989] reported that blue light irradiated first followed by UV-B on parsley cells increased the expression of CHS, a key enzyme in flavonoids biosynthesis. He explained that the effect of blue light on the expression of CHS was stable. Besides, Jenkins [1997] reported that blue light irradiated before UV-B resulted in an increase of CHS expression. That effect was not observed when UV-B was irradiated before blue light. These studies together with the present investigation suggest that blue light could generate a signal that enhanced subsequent response to UV-B and UV-C. This signal did not appear when the combination BL+UV-A was used. Therefore, blue light in combination of blue light and UV-B/UV-C generate a stable signal to enhance accumulation of flavonoids.

Blue light and UV-A/UV-C or their combinations also have an important influence on the relevant enzymes involved in flavonoids biosynthesis (Table 2). Blue light and UV-A/ UV-C or their combinations increased the activity of these enzymes (PAL, CHI and RDEs) significantly $(P<0.05)$ compared with darkness. The effect of blue light in combination with UV-A/UV-C on PAL, CHI and RDEs activity in tartary buckwheat sprouts was similar to that observed on total flavonoids content. That is, blue light in combination of blue light and UV-C increased PAL, CHI and REDs activity when blue light was irradiated first $(\mathrm{BL}+\mathrm{UV}-\mathrm{C})$ but showed little influence when combined with UV-A (BL+UV-A). Creasy [1968] found that the activity of PAL was correlated with the rate of flavonoids synthesis. Wang et al. [2013] reported

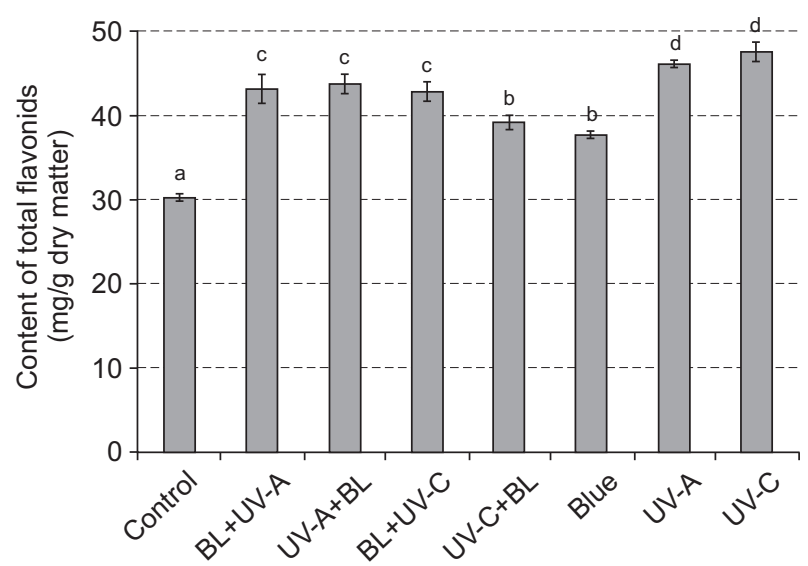

FIGURE 3. Effect of irradiation with different light combinations on the total flavonoids content in tartary buckwheat sprouts. Vertical bars indicate the standard deviation. BL+UV-A: irradiation with blue light followed by UV-A; UV-A+BL: irradiation with UV-A followed by blue light; BL+UV-C: irradiation with blue light followed by UV-C; UV-C+BL: irradiation with UV-C followed by blue light. Different letters show significant difference $(P<0.05)$.

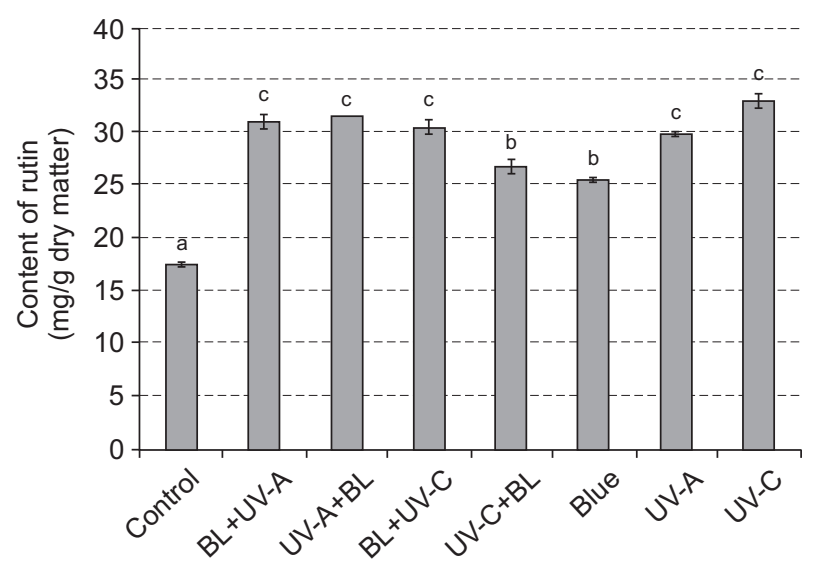

FIGURE 4. Effect of irradiation with different light combinations on the content of rutin in tartary buckwheat sprouts. Vertical bars indicate the standard deviation. BL+UV-A: irradiation with blue light followed by UV-A; UV-A+BL: irradiation with UV-A followed by blue light; BL+UV-C: irradiation with blue light followed by UV-C; UV-C+BL: irradiation with UV-C followed by blue light. Different letters show significant difference $(P<0.05)$.

that the effects of $\mathrm{Al}^{3+}, \mathrm{Cu}^{2+}$ and $\mathrm{Zn}^{2+}$ on the total flavonoids during germination of tartary buckwheat were in line with the activity of PAL and CHI. In the present work, the activity of PAL and CHI was in line with the variety of total flavonoids content as well. Therefore, blue light in combinations could influence flavonoids content by changing the activity of PAL and $\mathrm{CHI}$.

\section{Effect of light combinations on the levels of rutin and quercetin}

As previous studies reported, the flavonoid rutin has a high antioxidant activity [Yang et al., 2008] and quercetin is the degradation product of rutin, reaction catalyzed by RDEs. Stapleton \& Walbot [1994] and Lois [1994] indicated that the accumulation of flavonoids including rutin and quercetin prevent plants from environmental damage (such as ultraviolet). In this study, blue light and UV-A/C or 


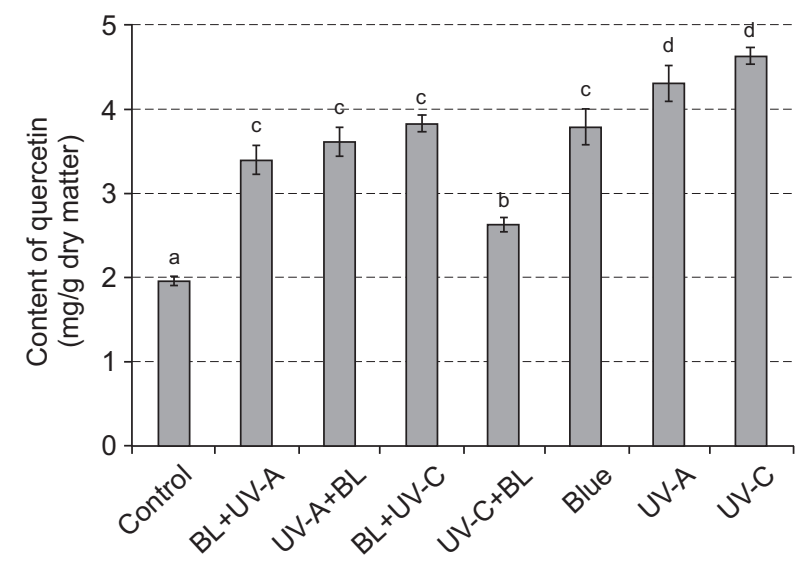

FIGURE 5. Effect of irradiation with different light combinations on the content of quercetin in tartary buckwheat sprouts. Vertical bars indicate the standard deviation. BL+UV-A: irradiation with blue light followed by UV-A; UV-A+BL: irradiation with UV-A followed by blue light; $\mathrm{BL}+\mathrm{UV}-\mathrm{C}$ : irradiation with blue light followed by UV-C; UV-C + BL: irradiation with UV-C followed by blue light. Different letters show significant difference $(P<0.05)$.

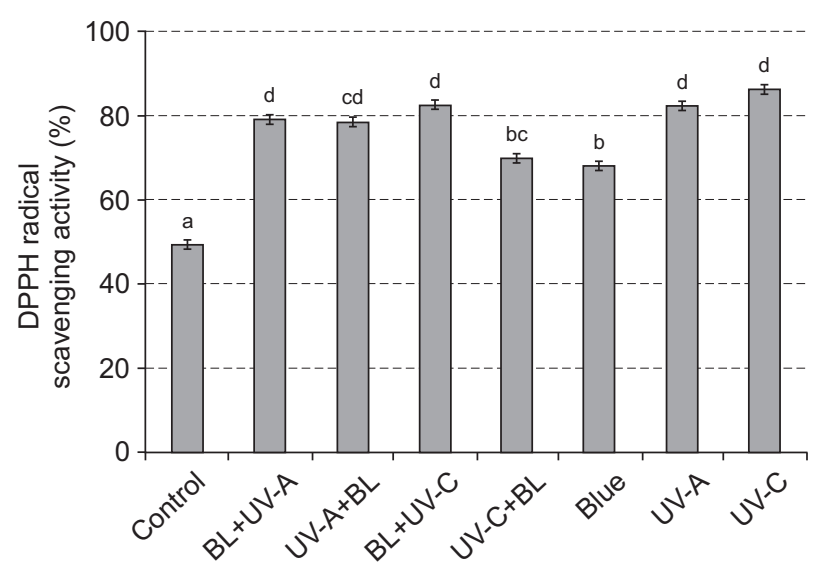

FIGURE 6. Effect of irradiation with different light combinations on DPPH radical scavenging activity in tartary buckwheat sprouts. Vertical bars indicate the standard deviation. BL+UV-A: irradiation with blue light followed by UV-A; UV-A+BL: irradiation with UV-A followed by blue light; $\mathrm{BL}+\mathrm{UV}-\mathrm{C}$ : irradiation with blue light followed by UV-C; UV-C + BL: irradiation with UV-C followed by blue light. Different letters show significant difference $(P<0.05)$.

their combinations significantly increased the levels of rutin (Figure 4) and quercetin compounds (Figure 5). The rutin contents in sprouts irradiated with UV-C and UV-A were 32.98 and $31.48 \mathrm{mg} / \mathrm{g}$ dry matter, respectively, which was higher than these of the others. The rutin content in irradiation with blue light irradiated first in combination of blue light and UV-C (BL+UV-C) was $13.5 \%$ higher than that of (UV-C $+\mathrm{BL})$, but it showed no difference in the sprouts irradiated with combination of UV-A and blue light either.

\section{DPPH radical scavenging activity}

The antioxidant activity of rutin was determined in this study as DPPH radical scavenging activity (Figure 6). DPPH radical scavenging activity in the UV-A and UV-C was approximately 1.48 fold higher than darkness. There were no differences from the statistical point of view between irradiation with UV-A, UV-C, and with the combinations BL+UV-A,
$\mathrm{UV}-\mathrm{A}+\mathrm{BL}$ and $\mathrm{BL}+\mathrm{UV}-\mathrm{C}$. Blue light and UV-A/UV-C or their combinations on DPPH radical scavenging activity showed the same trend than that of rutin content. Some previous studies indicated that among phenolic compounds, rutin had the highest radical scavenging activity [Watanabe, 2007] and it exhibited the strong DPPH radical scavenging activity [Yang et al., 2008]. Therefore, DPPH radical scavenging activity was greatly influenced by rutin content.

\section{CONCLUSION}

On the basis of the results obtained, we can conclude that blue light in combination with UV-C (BL+UV-C) enhanced the accumulation of bioactive compounds such as total flavonoids, rutin and quercetin in tartary buckwheat sprouts while this effect was not observed when it was combined with UV-A (BL+UV-A) .

\section{ACKNOWLEDGEMENT}

This research was financially supported by National Natural Science Foundation of China (31071527).

\section{REFERENCES}

1. Assis J.S., Maldonado R., Munoz T., Escribano M.I., Merodio C., Effect of high carbon dioxide concentration on PAL activity and phenolic contents in ripening cherimoya fruit. Postharv. Biol. Tecchnol., 2001, 23, 33-39.

2. Caldwell M.M., Bjorn L.O., Bomman J.F., Flint S.D., Kulandaivelu G., Teramura M., Tevini M., Effect of increased solar ultraviolet radiation on terrestrial ecosystem. J. Photoch. Photobiol. B., 1998, 46, 40-52.

3. Chen K., Feng H., Zhang M., Wang X., Nitric oxide alleviates oxidative damage in the green algae Chlorella pyrenoidosa caused by UV-B radiation. Folia Microbiol., 2003, 48, 389-393.

4. Chen P., Gu J.J., A rapid measurement of rutin-degrading enzyme activity in extract of tartary buckwheat seeds. Food Bioprod. Process., 2011, 89, 81-85.

5. Cortell J.M., Kennedy J.A., Effect of shading on accumulation of flavonoid compounds in (Vitis vinifera L.) pinot noir fruit and extraction in a model system. J. Agr. Food Chem., 2006, 54, 8510-852.

6. Creasy L.L., The increase in phenylalanine ammonia-lyase activity in strawberry leaf disks and its correlation with flavonoid synthesis. Phytochemistry, 1968, 3, 441-446.

7. Jenkins G.I., UV and blue light signal transduction in Arabidopsis plant. Plant Cell Environ., 1997, 20, 773-778.

8. Khatami F., Ghanati F., Effects of UV irradiation on cell viability, anthocyanin, and flavonoid contents of callus-cultured Malva neglecta cells. ICLST, 2011, 3, 202-204.

9. Kim S.L., Kim S.K., Park C.H., Introduction and nutritional evaluation of buckwheat sprouts as a new vegetable. Food Res. Int., 2004, 37, 319-327.

10. Koes R.E., Quattrocchio F., Mol J.N.M., The flavonoid biosynthetic pathway in plants: function and evolution. BioEssays, 1994, 16, 123-132.

11. Liang B., Huang X.H., Zhang G.S., Zhang F., Zhou Q., Effect of Lanthanum on plants under supplementary ultraviolet-B ra- 
diation: Effect of Lanthanum on flavonoid contents in soybean seedlings exposed to supplementary ultraviolet-B radiation. J. Rare Earth., 2006, 24, 613-616.

12. Lister C.E., Lancaster J.E., Walker J.R., Developmental changes in enzymes of flavonoid biosynthesis in the skins of red and green apple cultivars. J. Sci. Food Agr., 1996, 71, 313-320.

13. Lois R., Accumulation of UV-absorbing flavonoids induced by UV-B radiation in Ambidopsis thaliana L. Planta, 1994, 194, 498-503.

14. Matsuda R.K., Ohashi-Kaneko K., Fujiwara K., Kurata., Effects of blue light deficiency on acclimation of light energy partitioning in PSII and $\mathrm{CO}_{2}$ assimilation capacity to high irradiance in spinach leaves. Plant Cell Physiol., 2008, 49, 664-670.

15. Nakamura K., Naramoto K., Koyama M., Blood-pressure-lowering effect of fermented buckwheat sprouts in spontaneously hypertensive rats. J. Funct. Foods, 2013, 5, 406-415.

16. Nakajima K., Yoshie-Stark Y., Ogushi M., Comparison of ACE inhibitory and DPPH radical scavenging activities of fish muscle hydrolysates. Food Chem., 2009, 114, 844-851.

17. Ohl S., Hahlbrock K., Schăfer E., A stable blue light derived signal modulates ultraviolet light induced activation of the chalcone synthase gene in cultured parsley cells. Planta, 1989, 177, 228$-236$.

18. Pietta P.G., Flavonoids as antioxidants. J. Nat. Prod., 2000, 63, 1035-1042.

19. Stockova L., Matejova E., Janovska D., Sykorova S., Comparison of analytical methods for rutin determination in tartary buckwheat. Chem. Listy, 2009, 103, 827-831.

20. Saber N., Abou-Zeid H., Barakat S., Effect of radiation quality on phenylalanine ammonia-lyase and pigment content in the shoots of broad bean (Vicia faba) seedlings. Phyton (Horn, Austria), 1998, 38, 269-279.
21. Stapleton A.E., Walbot V., Flavonoids can protect maize DNA from the induction of ultraviolet radiation damage. Plant Physiol., 1994, 105, 881-889.

22. Tsurunaga Y., Takahashi T., Katsube T., Kudo A., Kuramitsu O., Ishiwata M., Matsumoto S., Effects of UV-B irradiation on the levels of anthocyanin, rutin and radical scavenging activity of buckwheat sprouts. Food Chem., 2013, 141, 552-556.

23. Takahata Y., Kai Y., Tanaka M., Nakayama H., Yoshinaga M., Enlargement of the variances in amount and composition of anthocyanin pigments in sweetpotato storage roots and their effect on the differences in DPPH radical-scavenging activity. Sci. Hort-Amsterdam, 2011, 127, 469-474.

24. Watanabe M., An anthocyanin compound in buckwheat sprouts and its contribution to antioxidant capacity. Biosci. Biotech. Biochem., 2007, 71, 579-582.

25. Wang L., Li X.D., Niu M., Wang R., Chen Z.X., Effect of additives on flavonoids, D-chiro-Inositol and trypsin inhibitor during the germination of tartary buckwheat seeds. J. Cereal Sci., 2013, 58, 348-354.

26. Whitelam G., Halliday K., Light and plant development. 2007. Blackwell Publishing, Oxford, UK.

27. Winkel-Shirley B., Flavonoid biosynthesis. A colorful model for genetics, biochemistry, cell biology, and biotechnology. Plant Physiol., 2001, 126, 485-493.

28. Yang J.X., Guo J., Yuan J.F., In vitro antioxidant properties of rutin. LWT-Food Sci. Technol., 2008, 41, 1060-1066.

29. Zhang M., An L., Feng H., Chen T., Chen K., Liu Y., Tang H., Wang C.H., The cascade mechanisms of nitric oxide as second messenger of ultraviolet - B in inhibiting mesocotyl elongation. Photochem. Photobiol., 2003, 77, 219-225.

Submitted: 3 August 2014. Revised: 2 May and 13 June 2015. Accepted 30 June 2015. Published on-line: 31 March 2016. 